\title{
TEACHING WITH MOODLE IN HIGHER EDUCATION
}

\author{
Ana Paula Lopes \\ Institute of Accounting and Administration - ISCAP \\ Polytechnic Institute of Oporto - IPP \\ PORTUGAL \\ aplopes@iscap.ipp.pt
}

\begin{abstract}
Nowadays, with the use of technology and the Internet, education is undergoing significant changes, contemplating new ways of teaching and learning. One of the widely methods of teaching used to promote knowledge, consists in the use of virtual environments available in various formats, taking as example the teaching-learning platforms, which are available online.
\end{abstract}

The Internet access and use of Laptops have created the technological conditions for teachers and students can benefit from the diversity of online information, communication, collaboration and sharing with others. The integration of Internet services in the teaching practices can provide thematic, social and digital enrichment for the agents involved.

In this paper we will talk about the advantages of LMS (Learning Management Systems) such as Moodle, to support the presential lectures in higher education. We also will analyse its implications for student support and online interaction, leading educational agents to a mixing of different learning environments, where they can combine face-to-face instruction with computer-mediated instruction, blended-learning, and increases the options for better quality and quantity of human interaction in a learning environment.

We also will present some tools traditionally used in online assessment and that are part of the functionalities of Moodle. These tools can provide interesting alternatives to promote a more significant learning and contribute to the development of flexible and customized models of an evaluation which we want to be more efficient.

Keywords: Higher Education, Technology, Moodle.

INTRODUCTION

With the use of technology, education took a big leap and is changing its paradigms, from a closed model, and teacher-centered classroom to a model more open and student-centered, where the teacher moves from one holder of knowledge for a learning mentor, able to manage diverse discourses and practices as well as stimulate the intellectual capacities of students in the treatment of information available. In network there is much valuable information, but there are also many errors and controversies instead of teaching may confuse the students. So, they generally have access to information, but do not always know to do with it. Nowadays, several tools can promote knowledge and learning, many practices were improved, such as audiovisual resources that were once closely tied to the television and video. Today, all were grouped in the same medium that is the Internet. The Internet is an excellent tool for use in the classroom because it allows extension of horizons, so that students learn to communicate and collaborate, encouraging, therefore, learning. But you also need to know how to use the Internet if otherwise the student will spend time to visit all the links, without 
retaining any information, because some of its features are the infinite amount of information available. Without proper care, the experiences in the classroom are not successful.

There are numerous environments that meet a set of features for creating and structuring of courses in the distance. These environments are also known LMS (Learning Management System) or learning management systems. Some of these environments used for creating and managing these online courses are: Moodle,TelEduc, BlackBoard, WebCT, Toolbook, TopClass Server, among others. These environments vary in many ways is the language they were developed, either in features and features each offers. LMS has the main objective to centralize and simplify administration and management of teaching and learning through e-learning. This system covers the entire process of distance learning, possessing interface and student teachers, tutors, to administrators and the administrative part. In this sense, helps employees and students to plan their learning processes, and let's work together, through the exchange of information and knowledge.

Among the main features of e-learning platforms we can refer to the flexibility, accessibility, focusing on the student, the economy or rationalization of resources, interactivity and enhancement of the student. The courses that are developed on the web have the advantage of providing the content for students anywhere in the world, faster than the other conventional methods distance education.

In addition, the communications resources of the web may make it more efficient to communication between teacher and students, when compared with other conventional methods.

The Moodle (Modular Object-Oriented Dynamic Learning Environment) platform an Open Source Learning Management System (OS LMS) is being used since 2005 in the Institute of Accounting and Administration of Porto - ISCAP, has been done in 2005. Although not directly interested in distance learning, ISCAP have been deeply involved since their very beginning in eLearning activities, mainly aimed at improving the quality of teaching/learning experience and at enhancing flexibility slightly reducing classes' time. ISCAP created in 2004 an Online Support Project (PAOL) whose main goal is offering pedagogical and technical support to all teachers and students.

\section{WHY AN OPEN SOURCE LEARNING MANAGEMENT SYSTEM}

The reasons that pushed ISCAP toward an Open Source (OS) solution are essential three and it concern costs, infrastructure and integration. One of the main issues with commercial LMS is funding: the uncertain benefits of online learning made the institution doubt about the real return of a huge investment as the acquisition of the required number of seats in a commercial LMS. First, teachers and students did not have established practices in using online tools, so that the actual use of the LMS was not predictable. Second, the uncertainties of the market and the rapid developments of the eLearning world made the commitment to a single producer tricky. Finally, in the undesired chance of a failure, the cost would have made almost impossible to try out another solution. Moving to an OS solution mitigated these three issues: given the low cost, even a failure would have a reduced impact on the overall budget, and would not have prevented moving to another OS or even commercial solution later.

The need of infrastructure, material and human resources, and of within work for setting up the system, for maintaining the application and for checking, selecting and installing updates. All of these issues are quite easy in our setting, as in most universities and institutes, who have a dedicated Information technology (IT) staff able to care after the infrastructure, the installation, maintenance and update of software applications. Furthermore, the hardware demands of OS software are usually significantly lower than those of commercial software.

In addition, an eLearning system should be integrated with the standard procedures for class scheduling, registration, evaluation, quality assessment, etc.

Therefore, one of the main advantages that an OS solution brings to institutional users is the possibility to tailor the application to one's needs, and to integrate it in first person in existing procedures and IT system. 
The name Moodle is an acronym for Modular Object Oriented term Developmental Learning Environment and is a course management system (Course Management System - CMS) through the Internet, also known as a Learning Management System (LMS) or a Virtual Learning Environment (VLE). It is a Free web application that educators can use to create effective online learning sites. One of its main advantages is its open source, or has open source allowing any user with programming knowledge to modify and adapt the environment according to their own needs.

Moodle can be installed at no cost at many servers. How has code opened there are no maintenance costs need to pay for upgrades. Nobody can force you to make updates, buy tools that you do not want or determine how many users should possess; the teacher manages the platform according to their needs.

This platform is widely used worldwide by universities, communities, schools, instructors, courses, teachers and even businesses. This system was developed by Martin Dougiamas, thanks to his background in education as in computing, managed to develop a tool with features technological and pedagogical satisfactory. The number of users and developers, who are working today in the form of collaborative communities to include more features in Moodle, has been increased. The great success Moodle is also due to the fact that the system is available to your code developers in various parts of the world to contribute new applications for the program, causing the system is today one of the most used in courses in the distance.

Although initially designed for higher education environment (university), Moodle has quickly become used across a broad range of organisations worldwide to conduct courses fully online or support faceto-face teaching and learning.

In reality, Moodle gives a less sophisticated and structured environment than a full-fledged commercial LMS such as WebCT for instance. As a result of the OS development model, Moodle looks more like a set of tools that share an environment, while commercial LMS support a complete development process and provide complex management tools. The question is that, given the simple necessities of our potential users, and the fact that online courses do not have any dedicated management process, a set of tools was far enough for our requirements.

The Moodle platform has three levels of use, with features of differential use and access. So is the concept of trustee or administrator (the manager of the platform), teacher (who may also have other designations, for example, trainer, facilitator, promoter) and the student (learner, participant, among others). These roles and their features are represented in the following table.

\begin{tabular}{|c|c|}
\hline Role & Function \\
\hline Administrator & Manages the whole environment \\
\hline Teacher & $\begin{array}{c}\text { Generate events, courses or subjects according to the thematic areas defined } \\
\text { Generate training or events which are designated }\end{array}$ \\
\hline Student & $\begin{array}{c}\text { Accesses and interacts with a specific event and participates in the subjects they } \\
\text { are subscribed }\end{array}$ \\
\hline
\end{tabular}

Fig.1. Roles and functions in Moodle Platform 
Moodle is composed of a simple interface that looks more like a portal of information; layout of this environment can be seen in Figure 2. In general, the pages of the courses are divided into three columns that can be customized by the teacher or the course, adding elements such as: calendar, online users, list of activities, among others.

These elements are arranged in columns to the right and left of the screen the user can be moved from one place to another teacher.

In the center column, we find a set of options that may be the result of the class through a list of topics numbered or dated weekly or, areas to group content or similar activities. In the center column of the courses that use Moodle as a virtual environment, there are generally living areas, for the record of course-related news, discussion forums, content areas to enter text, images and presentations on the theme, activities areas, to direct the tasks to be performed or delivered to the teacher or the central column, is the place where resources and activities are available.

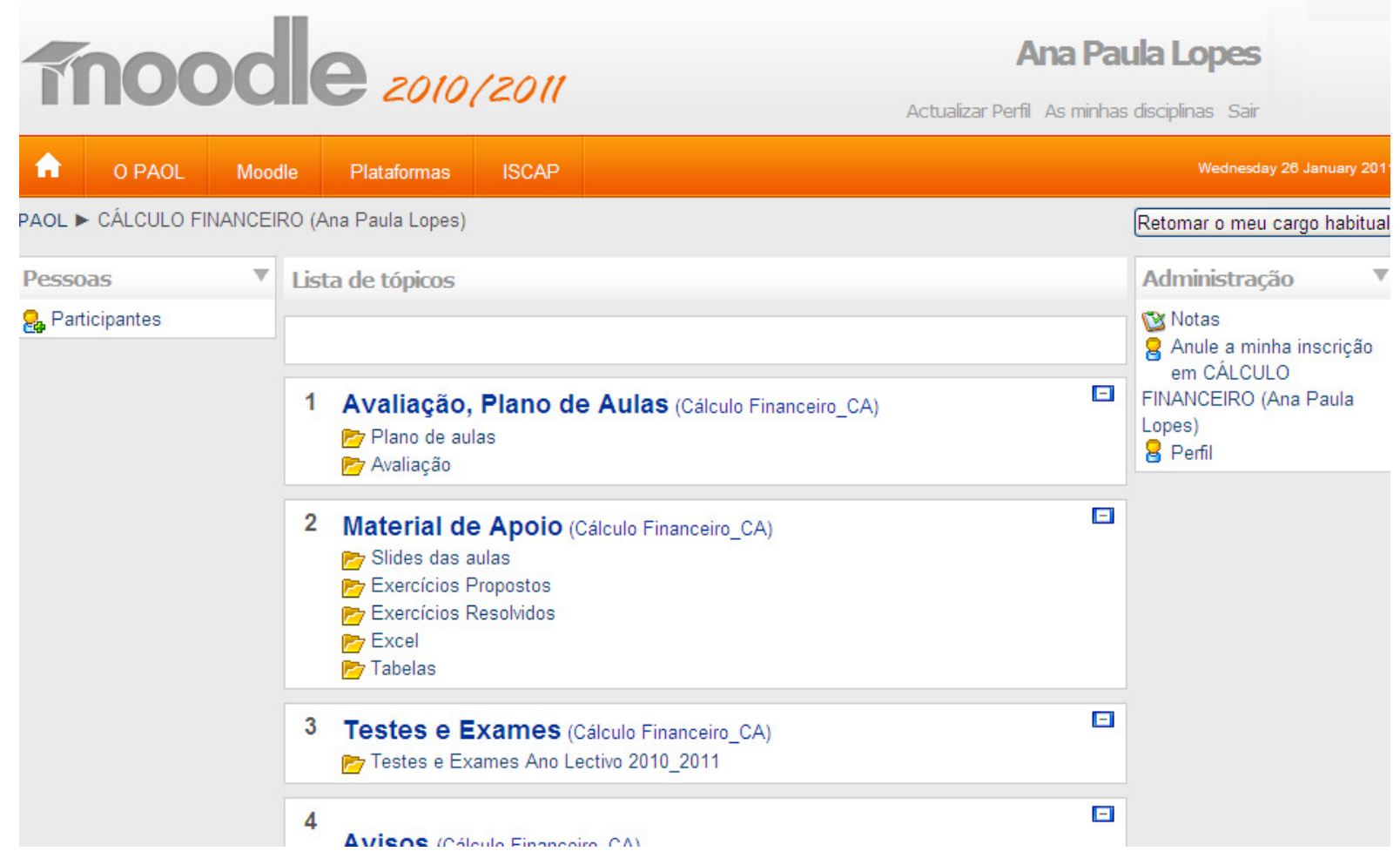

Fig.2. Layout of a page in Moodle

Through this environment, we can create various activities and use a set of tools that can be used according to each educational objective. We can see in the Figure 3 some activities in the Moodle platform.

\begin{tabular}{|l|}
\hline Adicionar uma actividade \\
\hline Adicionar uma actividade \\
\hline Chat \\
Diário de aluno \\
Fórum \\
Glossário \\
Inquérito \\
Lição \\
Referendo \\
SCORM/AICC \\
Tabela \\
Teste \\
Teste "Hot Potatoes" \\
Trabalhos \\
Envio de ficheiros avançado \\
Texto em-linha \\
Envio de um único ficheiro \\
Trabalho de casa \\
Wiki \\
\hline
\end{tabular}

Fig.3. Activities in Moodle 
Let's see what activities are available in Moodle:

\section{- $\quad$ CHAT}

The Chat module allows participants to have a real-time synchronous discussion. This is a useful way to get a different understanding of each other and the topic being discussed - the mode of using a chat room is quite different from typical internet forums. Chat contains a number of features for managing and reviewing chat discussions.

\section{- DATABASE}

The Database module allows the lecturer and/or students to build, display and search a bank of record entries about a topic. The format and structure of these entries can include images, files, URLs, numbers and text amongst other things. Although the database currently has issues exporting data for different modules, it is sometimes convenient to store and share data with all the participants. Database consists of multiple fields, which you need to create. You also set each database to decide how many entries each participant must write in order to view other entries, minimum and maximum entries one is allowed, and so on.

\section{- FORUNS}

Forums are used for asynchronous online discussion. By subscribing to a forum, participants receive copies of each new post by email. Teachers can impose subscription on everyone if they want to, and in this way can use a forum to contact all students on a course. They allow students and teachers to post comments in a central place to simulate (and stimulate) discussion. All Moodle courses automatically come with a News forum which cannot be removed, and all course participants will receive email whenever anything is added to that particular forum. However, you can add new forums as well.

\section{- GLOSSARY}

The Glossary activity allows participants to create and maintain a list of terms and definitions, as in a dictionary. It can be used to build an annotated list of useful websites or FAQs. The definitions can be searched or browsed in many different formats, and can be linked from other places on the site.

\section{- QUESTIONNAIRE}

The questionnaire module in Moodle allows you to create a survey or questionnaire for students to fill out, for instance a course evaluation or a reading response survey. You may choose whether or not the responses are anonymous.

\section{- SCHEDULER}

Scheduler is a Moodle Activity that allows the course instructor to post available meeting times and then has the students sign up for the slot that best suits them. This is useful for required meetings between student and professor, such as advising days, or simply for optional office hours.

\section{- LESSON}

A Lesson allows a lecturer to create conditional pathways through material. It consists of a number of pages, each page normally ending with a question and a number of possible answers. Depending on the student's choice of answer they either progress to the next page or are taken back to a previous page. When students answer a question, they are redirected to whatever page you'd like them to see next based on their answer. It can be a helpful tool for practicing material, studying, and testing. 
- $\quad$ HOT POTATOES

The Hot Potatoes module, allows teachers to administer Hot Potatoes quizzes via Moodle.

\section{- $\quad$ ASSIGNMENTS}

Assignments allow students to submit work online, including uploading any file type (Word document, Powerpoint, video clip etc.). Lecturers can grade and give feedback.

\section{Advanced Uploading of Files}

This option should be used when you want your students to be submitting multiple files, or particularly big files. In this sub-module, you will be able to set a maximum file size as well as a maximum number of files submitted per student, and you can decide if you want students to work in groups, if students can delete files after they are uploaded, if students can write notes to you online, and when the assignment is due. You can also decide whether you would like to receive an email every time a student submits a file. This assignment has a further feature of allowing teachers to submit feedback in the form of a file, so an electronically corrected document may be returned. For detailed documentation on this, see the Advanced Assignments PDF on the right side of this page.

\section{Online Text}

This option is for relatively short, text-based assignments. For example, if you wanted to ask students to submit their thoughts on a reading assignment, you might use this kind of assignment. Students will not be able to upload files from their computer; they will simply see a text editor box, approximately paragraph-sized, where they can type something up online and submit it to you.

In the sub-module, you can set things like due dates, whether late assignments are acceptable, whether assignments can be resubmitted, and whether you would like to receive email alerts when a submission has been made. You can also make the submissions easier to grade by turning on the "Comment inline" option, which will allow you to edit the original text, or comment using a different color. Furthermore, you can split students into groups, but this is generally a solitary kind of assignment.

\section{Upload Single File}

If you would like to have your students upload files, but you only want each student to upload one file and the files aren't particularly big (Word documents, Excel spreadsheets, etc.), then you can use the much simpler "Upload a single file" option, which works almost exactly like "Advanced uploading of files", except for the number limit on each student. As a professor, you can set a grade scale, due date, late submission policy, and resubmission policy, as well as a maximum size of file. You can also split students into groups and have each group submit one assignment, and decide whether you would like email alerts when files are submitted.

\section{Offline Activity}

This is the easiest option to use. There is no online submission of any kind; the assignment mostly exists as a reminder to students that they have a certain assignment due on a certain day. Mostly, this is used for assignments from the textbook, or offline worksheets. You can set a grading scale, a due date, and a late submission policy, but again, this is all for the students' benefit, since they won't be submitting anything online, anyway.

\section{- $\quad$ QUIZ}

The Quiz module allows the lecturer to design and set quiz tests, and includes a range of question types and reporting options. Moodle Quizzes are a great resource for every professor. Electronic quizzes can do many things that paper quizzes just can't. You can create different question types, randomly generate quizzes from pools of questions, allow students to retake quizzes multiple times, and have the computer score it all. These features open up a world of possibilities that just aren't practical with paper-based testing. 
Moodle quizzes have two components: the quiz body and the question pools. The body is the final quiz that a student will see, after all the randomizing and question-picking--it is the "container" for the various questions pulled from the question pools. You can define rules for how the body pulls from the pools: for example, you might create three question pools, one for each chapter that you are testing, and tell the quiz body to pull five questions from the first chapter, two questions from the second chapter, and three from the third chapter. Pools can be reused, shared between classes, and moved between systems.

\section{- WIKI}

A Wiki enables documents to be authored collectively. A history of all contributions and changes is stored and the wiki can be rolled back to a previous version at any time.

Wikis can be formatted with Wiki Markup or with HTML if the wiki has been given that option.

\section{- WORKSHOP}

A Workshop is a peer assessment activity. It allows participants to assess each other's projects, as well as exemplar projects, in a number of ways. The key to the Workshop is the scoring guide, which is a set of specific criteria for making judgments about the quality of a given work. This helps to provide a framework for both instructor and peer feedback on openended assignments, such as essays and research papers.

\section{- SCORM}

Moodle has an embedded module for both SCORM or AICC formats that allows you to easily create, reuse, and transfer your (or someone else's) custom training content to and from other course management systems (and from some text book resources).

\section{- SURVEY}

Moodle's surveys can give feedback on how useful certain aspects of coursework are. There are currently only five pre-designed surveys to choose from; you cannot write your own survey at present.

\section{Types of surveys:}

- ATTLS: The Attitudes Toward Thinking and Learning Survey (ATTLS) is a twenty-question survey that gives an idea of the learning attitudes of students. It distinguishes between "connected knowers" and "separate knowers", where connected knowers favor interaction and cooperation but separate knowers prefer argumentative learning.

- Critical Incidents: The critical incidents survey provides five free-response questions about what was effective and ineffective in class and in forums.

- Colles: The Constructive On-Line Learning Environment Survey (Colles) provides feedback on the effectiveness of certain aspects of on-line learning. Each of the three versions has the same 24 questions divided into six categories.

- Colles (Actual): This version of Colles asks students about what actually happened.

- Colles (Preferred and Actual): This version of Colles asks students each question twice, the first time to find out what the student wanted and the second to find out what actually happened.

- Colles (Preferred): This version of Colles asks students what they want to get out of an on-line unit. 
The Moodle is an e-learning platform used throughout the world. Universities, communities, schools and teachers serve up to her to communicate and transmit information to their educational communities. Developed by Martin Dougiamas is a platform with technological characteristics and satisfactory teaching, gaining users and developers working collaboratively. The great success of this platform due to the fact that a open source system, providing programmers the opportunity to make new contributions, with new applications, making it one of the most widely used in courses distance. It seems to us that the integration of such platforms deserves special attention and should be included in educational settings, despite all the limitations and lack of existing at the different levels, such as difficulty in accessing the platform, because the connections are very slow or that the servers can not manage the information when there are many users, or because there is no availability of computers with Internet connection.

\section{REFERENCES}

[1] Cook, J. (2001). The Role of Dialogue in Computer-Based Learning and Observing Learning: An Evolutionary Approach to Theory. Journal of Interactive Media in Education, 2001(Theory for Learning Technologies). http://www-jime.open.ac.uk/2001/cook/cook-t.html

[2] Dougiamas, M. (2001). Moodle: open-source software for producing internet-based courses. http://dougiamas.com/

[3] Dougiamas, M. and Taylor, P.C. (2003) Moodle: Using Learning Communities to Create an Open Source Course Management System. Proceedings of the EDMEDIA 2003 Conference, Honolulu, Hawaii.

[4] Bottentuit Junior. J.B. (2007). Laboratórios Baseados na Internet: Desenvolvimento de um laboratório virtual na plataforma MOODLE. Dissertação de Mestrado em Educação Multimédia. Faculdade de Ciências da Universidade do Porto, Porto.

[5] Rauhvargers, A. and Rusakova, A. (2010). Improving recognition in the European Higher Education Area: an analysis of national action plans (Council of Europe higher education series No.12) 